\title{
The effect of sling exercise on sagittal lumbosacral angle and intervertebral disc area of chronic low back pain patients
}

\author{
Seung-Bum Lee', Won-Je Cho ${ }^{2, *}$ \\ 'Department of Physical Education, Gyeongin National University of Education, Incheon, Korea \\ 2Department of Physical Education, College of Education, Dankook University, Yongin, Korea
}

The purpose of this study was to observe the change of lumbosacral angle and intervertebral disc (IVD) area. The study was conducted on chronic low back pain (CLBP) female patients for 12 weeks by operating sling exercise and general physical therapy. The 57 CLBP were divided into 2 groups which, sling exercise group (SEG, $n=34$ ) and general physical therapy group (PTG, $n=23$ ). The experiment was conducted three times a week for 12 weeks. The lumbosacral angle, which means the angle between the L1-L2 lumbar was measured by plain radiography. The IVD area, which means the IVD height and volume was measured by magnetic resonance imaging. The pain was measured by vi- sual analogue scale (VAS). As a result, after 12-week exercise, VAS had decreased in all groups. The angle of $L 3-4$ and $L 4-5$ and the height of IVD had increased in SEG. Also, IVD height and volume has more improved in SEG compare the PTG. Therefore, the sling exercise is proper treatment for CLBP patients' recovery because It improve the lumbosacral angle and IVD area.

Keywords: Lumbosacral angle, Intervertebral disc area, Visual analogue scale, Chronic low back pain, Sling exercise

\section{INTRODUCTION}

Acute low back pain can be cured in 10-12 weeks by conservative treatment (Van Tulder et al., 2000). However, $60 \%-75 \%$ of Korean patients who recovered from acute back pain have experiences of recurrence, $7 \%-10 \%$ of those have somatoform disorders caused by chronic low back pain (CLBP) (Korea Centers for Disease Control \& Prevention, 2014). The result was reported that to reduce low back pain (LBP), exercise for muscle strengthen of lumbosacral part therapy is more effective to stabilize pelvic than physical therapy or pharmacotherapy which could be passive treatment (Carpenter and Nelson, 1999). It is common fact that sling exercise may reduce the pain by increase space of intervertebral disc (IVD) (MacDonald et al., 2006), however, LBP may recur and increase the pain when muscular strength of lumbosacral part is weakened (Verbunt et al., 2010). Therefore, Legaye and Duval-Beaupere (2008) announced focusing on the normal spinal alignment recovery is more appropriate to recover CLBP than recovery of muscular strength.

If the spinal alignment over the normal range, the pain in particular part could be occurred by localized compression in vertebrae joint and IVD (Mac-Thiong et al., 2004). According to the increase of sedentary lifestyles, lumbosacral-pelvic sagittal alignment (LSA) over of normal range and also patient who complained of LBP is increasing recently (Mac-Thiong et al., 2004).

When the lumber intervertebral are outside the normal range, the spinal nerve near the vertebral is stimulated by lumber IVD and it cause the pain. Therefore, for the accurate assessment the study that observing the IVD area of lumber and lumbosacral IVD angle is needed.
${ }^{*}$ Corresponding author: Won-Je Cho (i) http://orcid.org/0000-0001-5256-8341 Department of Physical Education, College of Education, Dankook University, 152, Jukjeon-ro, Suji-gu, Yongin 16890, Korea

Tel: +82-31-8005-3867, Fax: +82-31-8021-7232, E-mail: dkwonje24@naver.com Received: June 30, 2016 / Accepted: October 2, 2016
This is an Open Access article distributed under the terms of the Creative Commons Attribution Non-Commercial License (http://creativecommons.org/licenses/by-nc/4.0/) which permits unrestricted non-commercial use, distribution, and reproduction in any medium, provided the original work is properly cited. 
Therefore, this study was conducted to find the effect of sling exercise on rehabilitation of normal range of angle. The study involved women with a high risk of CLBP. The change of lumbosacral IVD area and angle of the participants were observed.

\section{MATERIALS AND METHODS}

\section{Research participants}

The subjects of this study was the patients who did not get spiral surgery or did not have fracture, tumor, inflammation, metabolic disease in Ho hospital which is located in Yongin-si, Gyeonggi-do, South Korea. The patients were divided into a sling exercise group (SEG, $n=34$ ), whose mean age, height, weight, and body mass index (BMI) were $43.61 \pm 10.27$ years, $161.11 \pm 3.37$ $\mathrm{cm}, 56.74 \pm 4.31 \mathrm{~kg}$, and $21.85 \pm 1.41 \mathrm{~kg} / \mathrm{m}^{2}$, respectively, and a general physical therapy group (PTG, $\mathrm{n}=23$ ), whose mean age, height, weight, and BMI were $45.08 \pm 10.43$ years, $161.39 \pm 3.37$ $\mathrm{cm}, 58.62 \pm 5.42 \mathrm{~kg}$, and $22.48 \pm 1.52 \mathrm{~kg} / \mathrm{m}^{2}$, respectively. There were no significant differences between groups with respect to baseline characteristics. All patients read and signed informed consent forms in accordance with the ethical standard of the Declaration of Helsinki.

\section{Sling exercise and physical therapy program}

The two treatment programs, consisting of sling and general physical therapy, were conducted three times a week for 12 weeks. The sling exercise program was part of the trunk and pelvic stability exercise that consisted of 6 movements: stretching of trunk-pelvis, hip-trunk bridging exercise, pelvic tilting exercise (anterior, posterior, and lateral side), low crossed exercise, trunk rotation exercise, Oscillate exercise of trunk-pelvis were carried out through supine position. Each action was performed 10-15 times for one set and repeated 3 times, and there were 90-sec rest time between each set. In the event of pain or muscle paralysis, exercise was suspended. Each action was orally described to the patient. Additionally, 15-20 min in of superficial heating (heat pack) were provided followed by $5 \mathrm{~min}$ of ultrasound treatment (SM-250, Samson Med, Seoul, Korea) using a $1 \mathrm{MHz}$ with $5 \mathrm{~cm}^{2}$ in sound head at an intensity of $1.5 \mathrm{~W} / \mathrm{cm}^{2}$ in continuous mode and, 15-20 min of interferential current treatment (SM-850P, Samson Med, Seoul, Korea) at an intensity of $25 \mathrm{~mA}$. The 15-20 min of traction treatment was conducted also when the patients felt extra exercise is needed, light walking was allocated to the patients. The pelvic incedence was measured by plain radiography (R-630-150, Dongkwang, Seoul, Korea) of the lumbar region and
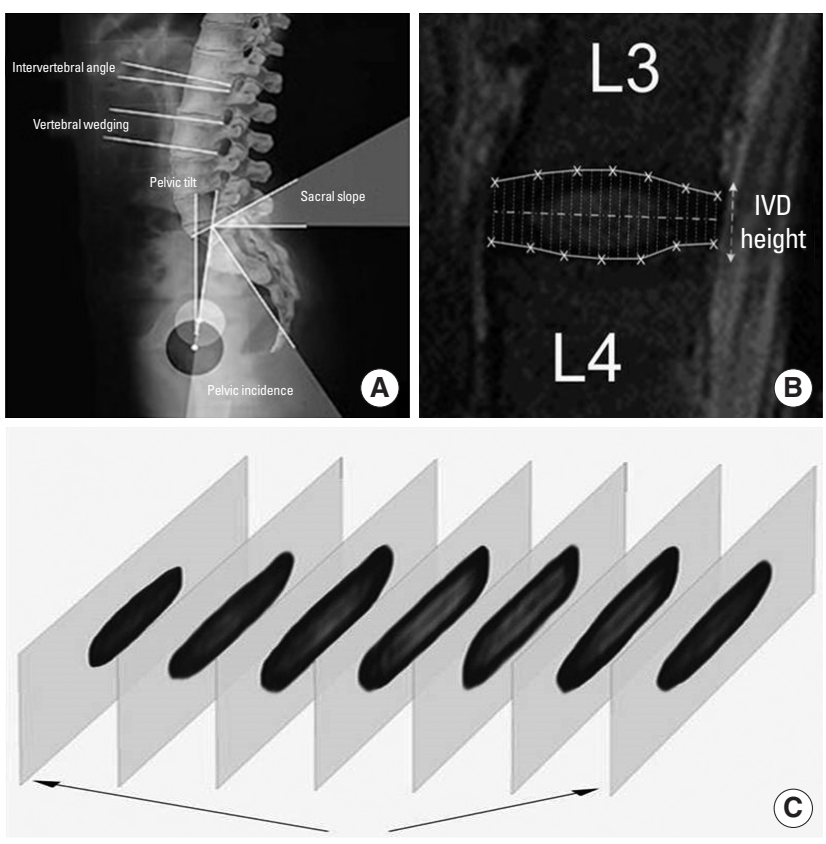

Fig. 1. (A) The lumbar and pelvic parameters used in the current study (Vialle et al., 2007). (B) Three-dimensional reconstruction of an example intervertebral disc (IVD). (C) Mean IVD height was calculated from IVD height in all magnetic resonance imaging slices, and IVD height values were integrated to calculate IVD volume (Kingsley et al., 2012).

magnifying the images 3 times by using a picture archiving and communication system (PACS; Infiniff, Seoul, Korea). Each patient underwent a $30 \times 90-\mathrm{cm}$ lateral radiography of the lumbosacral region, printed on acetate with the individual standing, knees extended, and flexed arms in front. Care was taken to ensure that the radiography included both femoral heads. If the femoral heads did not overlap in the radiograph, the midpoint of the line connecting the isocenter of both femoral heads was taken as a reference point.

\section{The measurement of lumbosacral angle}

The measurement of lumbosacral angle and magnetic resonance imaging (MRI) showed Fig. 1. Using radiography equipment of diagnosis X-ray model 630-125, sagittal lumbosacral part image was scanned by radiation specialist. It was the same way from the study of Jackson and McManus (1994). Each lumber IVD angle was measured from standing position to lumber 1-5. The way of Measurement was to check the angle of intersection between two lines (vertebrae inferior surface of lumber and vertebrae upper surface of lumber). To measure the lumbosacral angle, the angle of intersection between two lines (inferior surface of lumber 5 and upper surface of sacral) was measured. 


\section{Magnetic resonance imaging}

MRI examinations were carried out in the supine position, lasting between 7 and $10 \mathrm{~min}$. The MRI protocol was performed on a 1.5-T high-definition 16-channel system (GE Medical Systems, Waukesha, WI, USA). The field of view was $71 \mathrm{~cm}$ for the sagittal images with an image matrix of $352 \times 320$ and a number of excitations was equal to 4 . The lumbar images were obtained in separate sections and subsequently fused using the MRI pasting software on the workstation (Advantage Windows, GE Healthcare). All images were stored in DICOM format, exported as uncompressed full-size images (Centricity; GE Healthcare), and imported into LabVIEW for digitization (Professional ver. 10.0; National Instruments, Austin, TX, USA).

These digitized points were interpolated in 1-mm intervals, and these coordinates were used to determine the distance between adjacent vertebral endplates. Digitization was performed by a single operator after extensive training and familiarization. The images derived from the MRI scan were combined to produce a digital three-dimensional representation of lumbar IVDs to determine mean vertical IVD height and to calculate IVD volume.

\section{Visual analog scale}

A visual analog scale (VAS) was used to measure the degree of LBP. The VAS was developed in 1974 by Huskisson (1974). Subjects check the degrees of subjective pain on a 10-cm line, on which $0 \mathrm{~cm}$ indicates "no pain: at the left end and $10 \mathrm{~cm}$ indicates "very sever pain" at the fight end. The vas score is determined as the measurement from the left side, with a higher score meaning a more severe pain intensity of the low back.

\section{Research procedures and data analysis}

Data were statistically analyzed using IBM SPSS Statistics ver. 22.0 (IBM Co., Armonk, NY, USA). All data using Paired and independent $t$-tests were performed for intra and intergroup comparisons, VAS, lumbosacral angle, and IVD area. To evaluate the pre and post change rate in each group. \% delta score was calculated, statistical significance was accepted at values of $a<0.05$.

\section{RESULTS}

This study of results was shown in Table 1. There were no VAS differences between SEG and PTG but after the treatment, both of SEG and PTG significantly decreased $(t=22.595, P<0.001)$ $(t=18.143, P<0.001)$. However, there were no L1-2 and L2-3 differences in SEG and PTG. In SEG, L3-4 and L4-5 were con-
Table 1. The change of VAS, lumbosacral angle, intervertebral disc area by treatments

\begin{tabular}{|c|c|c|c|}
\hline Variable & & SEG $(n=34)$ & PTG (n=23) \\
\hline \multirow[t]{3}{*}{ VAS (score) } & Pre & $5.82 \pm 0.65$ & $6.11 \pm 0.84$ \\
\hline & Post & $2.60 \pm 0.65^{* * *, b)}$ & $2.64 \pm 0.54^{* * *, b)}$ \\
\hline & $\Delta \%$ & $-56.19 \pm 9.62$ & $-54.88 \pm 11.54$ \\
\hline \multirow[t]{3}{*}{$\mathrm{L} 1-\mathrm{L} 2\left(^{\circ}\right)$} & Pre & $4.66 \pm 2.44$ & $5.43 \pm 1.90$ \\
\hline & Post & $5.19 \pm 1.40$ & $6.16 \pm 3.71$ \\
\hline & $\Delta \%$ & $52.84 \pm 113.89$ & $23.45 \pm 68.43$ \\
\hline \multirow[t]{3}{*}{$\mathrm{L} 2-\mathrm{L} 3\left(^{\circ}\right)$} & Pre & $7.06 \pm 2.72$ & $6.83 \pm 2.19$ \\
\hline & Post & $6.79 \pm 1.60$ & $6.56 \pm 2.58$ \\
\hline & $\Delta \%$ & $13.59 \pm 65.41$ & $0.49 \pm 30.32$ \\
\hline \multirow[t]{3}{*}{ L3- $-\mathrm{L} 4\left(^{\circ}\right)$} & Pre & $8.57 \pm 2.39$ & $8.78 \pm 3.09$ \\
\hline & Post & $9.40 \pm 2.12^{*}$ & $8.63 \pm 2.77$ \\
\hline & $\Delta \%$ a) & $15.13 \pm 31.28$ & $0.28 \pm 16.26$ \\
\hline \multirow[t]{3}{*}{$L 4-L 5\left(^{\circ}\right)$} & Pre & $8.54 \pm 4.37$ & $10.36 \pm 4.92$ \\
\hline & Post & $10.46 \pm 2.81^{* *, b)}$ & $9.87 \pm 3.44$ \\
\hline & $\Delta \%$ al & $56.16 \pm 92.73$ & $15.96 \pm 58.16$ \\
\hline \multirow[t]{3}{*}{ L5-S1 ( $\left.{ }^{\circ}\right)$} & Pre & $14.50 \pm 5.63$ & $14.15 \pm 4.21$ \\
\hline & Post & $14.43 \pm 2.76$ & $14.20 \pm 3.61$ \\
\hline & $\Delta \%$ & $50.07 \pm 74.33$ & $87.19 \pm 195.81$ \\
\hline \multirow[t]{3}{*}{ IVD height (mm) } & Pre & $3.90 \pm 3.36$ & $3.99 \pm 2.81$ \\
\hline & Postal & $4.01 \pm 2.86^{*, b l}$ & $3.84 \pm 2.80$ \\
\hline & $\Delta \%$ a) & $0.51 \pm 3.20$ & $-1.40 \pm 4.51$ \\
\hline \multirow[t]{3}{*}{ IVD volume $\left(\mathrm{mm}^{3}\right)$} & Pre & $1,720.35 \pm 265.62$ & $1,680.09 \pm 289.39$ \\
\hline & Post $t^{\mathrm{al}}$ & $1,820.04 \pm 312.49$ & $1,617.54 \pm 277.39$ \\
\hline & $\Delta \%$ & $9.34 \pm 29.49$ & $-0.52 \pm 25.31$ \\
\hline
\end{tabular}

Values are presented as mean \pm standard deviation.

SEG, sling exercise group; PTG, general physical therapy group; VAS, visual analog scale; IVD, intervertebral disc; $\Delta \%$, delta score.

allndependent $t$-test. ${ }^{\text {blPaired } t \text {-test. }{ }^{*} P<0.05 .{ }^{* *} P<0.01 .{ }^{* *} P} P<0.001$.

siderably increased $(t=-2.862, P<0.05)(t=-3.088, P<0.01)$, the rate of change in SEG was significantly higher than PTG $(t=2.090, P<0.05)(t=2.076, P<0.05)$. Also, after treatment, there were considerable differences in the height of IVD between SEG and PTG $(t=-2.246, P<0.05)$. The height of IVD was not changed in PTG but after treatment, the height of IVD was increased in SEG $(t=2.044, P<0.05)$. The rate of change of SEG was higher than the PTG's $(t=-2.039, P<0.05)$. As a result, The IVD volume of SEG was greater compare to PTG $(t=-2.022$, $P<0.01$ )

\section{DISCUSSION}

CLBP means pain which lasts more than 12 weeks (Merskey and Bogduk 1994). The general reason of back pain is compression of spinal nerve by partially herniated IVD. It occurs when the 
lumbosacral angle, L1 to L5 and S1, was changed (Glavas et al., 2009). The increase or decrease of lumbosacral lordosis provides the weight bearing to spine and IVD. It causes the compression of neuromuscle, muscle stiffness and disc degeneration (Verbunt et al., 2010). Therefore, recovery to normal lumbosacral angle is the main cause of the reducing LBP (Legaye and Duval-Beaupere, 2008).

There were correlation between IVD of lumber and volume. If the volume of IVD is small and low, it increased the pain. Therefore, the improvement of IVD volume is the important factor to recover the pain (Derby et al., 2005).

As a result, for CLBP patients, sling exercise and physical therapy both had effect on decreasing VAS. However, there were differences between sling exercise and physical therapy in lumbosacral angle and IVD area. After physical therapy, the lumbosacral angle and IVD area was not changed. However, after sling exercise, angle of L3-4, L-5, and IVD height was increased. Also, IVD height and volume was more improved after sling exercise compare to physical therapy. The sling exercise increases the IVD area and reduces the pain by recovery muscle strength (MacDonald et al., 2006).

This kind of method can relieve pain by stimulating coordination of proprioception sense neuromuscular system which maintain posture (Kim and Kim, 2013). As a result of doing neurac sling exercise which is the vibration stimulus exercise using hanging rope for 12 weeks, it helps to stabilize low back and posture balance and increases neuromuscluer to CLBP patient (Kim and Kim, 2013). Also after doing sling exercise and push-up for 6 weeks, doing both exercise is more effective for LSA than doing only sling exercise (Kim et al., 2013).

The results of this study, the IVD height and volume in the CLBP showed significantly lower than the healthy women (Kingsley et al., 2012). However, physical therapy did not change the height and volume of the IVD. But sling exercise was would be able to indicate the height and volume of IVD was improved delayed regression of IVD of lumbar.

Among the intervention treatment for normal spinal alignment of patient with CLBP, the effect of laser, massage and spinal manipulation therapy is temporary. However, aquatic therapy, magnetic therapy, tramscutaneous electrical nerve stimulation, Ultrasonic, acupuncture and pilates were reported it has no effect or the effect is unclear (Maher, 2004).

The exercise therapy for lumbosacral misalignments and recovery of normal lumbosacral angle improves muscle strength and stability of lumbosacral alignment. However, there are various re- sults by types of exercises (Akuthota and Nadler, 2004; Chanplakorn et al., 2011; Taylor et al., 2007). When this study and preceding study were combined, the lumbar multifidus strength, lumbosacral angle and IVD were improved by the sling exercise. Therefore, the sling exercise is proper treatment to recover the CLBP of patients.

\section{CONFLICT OF INTEREST}

No potential conflict of interest relevant to this article was reported.

\section{REFERENCES}

Akuthota V, Nadler SF. Core strengthening. Arch Phys Med Rehabil 2004;85(3 Suppl 1):S86-92.

Carpenter DM, Nelson BW. Low back strengthening for the prevention and treatment of low back pain. Med Sci Sports Exerc 1999;31:18-24.

Chanplakorn P, Wongsak S, Woratanarat P, Wajanavisit W, Laohacharoensombat $\mathrm{W}$. Lumbopelvic alignment on standing lateral radiograph of adult volunteers and the classification in the sagittal alignment of lumbar spine. Eur Spine J 2011;20:706-712.

Derby R, Kim BJ, Lee SH, Chen Y, Seo KS, Aprill C. Comparison of discographic findings in asymptomatic subject discs and the negative discs of chronic LBP patients: can discography distinguish asymptomatic discs among morphologically abnormal discs? Spine J 2005;5: 389-394.

Glavas P, Mac-Thiong JM, Parent S, de Guise JA, Labelle H. Assessment of lumbosacral kyphosis in spondylolisthesis: a computer-assisted reliability study of six measurement techniques. Eur Spine J 2009;18:212217.

Huskisson EC. Measurement of pain. Lancet 1974;2:1127-1131.

Jackson RP, McManus AC. Radiographic analysis of sagittal plane alignment and balance in standing volunteers and patients with low back pain matched for age, sex, and size. A prospective controlled clinical study. Spine (Phila Pa 1976) 1994;19:1611-1618.

Kim GY, Kim SH. Effects of push-ups plus sling exercise on muscle activation and cross-sectional area of the multifidus muscle in patients with low back pain. J Phys Ther Sci 2013;25:1575-1578.

Kim JH, Kim YE, Bae SH, Kim KY. The effect of the neurac sling exercise on postural balance adjustment and muscular response patterns in chronic low back pain patients. J Phys Ther Sci 2013;25:1015-1019.

Kingsley MI, D'Silva LA, Jennings C, Humphries B, Dalbo VJ, Scanlan AT. Moderate-intensity running causes intervertebral disc compression in young adults. Med Sci Sports Exerc 2012;44:2199-2204. 
Korea Centers for Disease Control \& Prevention. 2013 Health behavior and chronic disease statistics. Cheongju: Korea Centers for Disease Control \& Prevention; 2014.

Legaye J, Duval-Beaupere G. Gravitational forces and sagittal shape of the spine. Clinical estimation of their relations. Int Orthop 2008;32:809816.

MacDonald DA, Moseley GL, Hodges PW. The lumbar multifidus: does the evidence support clinical beliefs? Man Ther 2006;11:254-263.

Mac-Thiong JM, Berthonnaud E, Dimar JR 2nd, Betz RR, Labelle H. Sagittal alignment of the spine and pelvis during growth. Spine (Phila Pa 1976) 2004;29:1642-1647.

Maher CG. Effective physical treatment for chronic low back pain. Orthop Clin North Am 2004;35:57-64.

Merskey H, Bogduk N. Classification of chronic pain: description of chronic pain syndromes and definition of pain terms. 2nd ed. Seattle (WA): IASP Press; 1994.

Taylor NF, Dodd KJ, Shields N, Bruder A. Therapeutic exercise in physiotherapy practice is beneficial: a summary of systematic reviews 20022005. Aust J Physiother 2007;53:7-16.

van Tulder MW, Ostelo R, Vlaeyen JW, Linton SJ, Morley SJ, Assendelft WJ. Behavioral treatment for chronic low back pain: a systematic review within the framework of the Cochrane Back Review Group. Spine (Phila Pa 1976) 2000;25:2688-2699.

Verbunt JA, Smeets RJ, Wittink HM. Cause or effect? Deconditioning and chronic low back pain. Pain 2010;149:428-430.

Vialle R, Dauzac C, Khouri N, Wicart P, Glorion C, Guigui P. Sacral and lumbar-pelvic morphology in high-grade spondylolisthesis. Orthopedics 2007;30:642-649. 